\title{
Exploring Polish migrants' adaptation to life in the UK: an interpretative phenomenological analysis
}

\section{Paul O’Brien and Rachel Tribe}

Paul O'Brien, Psychological Services, Goodmayes Hospital, North East London NHS Foundation Trust, London, UK. *Corresponding author. Email: pfobrien@gmail.com

Rachel Tribe, School of Psychology, University of East London, London, UK

Accepted for publication 10 September 2013 in International Journal of Culture and Mental Health

\begin{abstract}
This paper presents findings from a study exploring how a group of post-2004 Polish migrants reported adapting to life in the UK. Eight participants were interviewed and transcripts were analysed using the qualitative methodology of interpretative phenomenological analysis. Two themes encapsulating the main findings from the study form the focus of the paper: in pursuit of more freedom and disconnection. From the analysis, it appears that this sample is particularly motivated by the opportunity for personal growth, which is perceived as more achievable in the UK. It is contended that this reflects a pre-existing identification with more individualist characteristics associated with 'Western culture', which participants, in the postcommunist landscape of Poland, have internalised. The sense of disconnection experienced by participants relates to difficulties forming friendships in the UK and is understood as a consequence of differing cultural values associated with social relationships. Contextual factors for each of these domains are considered. The findings represent the reported experiences of this group of participants and may not be generalizable.
\end{abstract}

Keywords: adaptation; migration; Polish; interpretative phenomenological analysis 


\section{Introduction}

Polish migration to the UK

Migration from Poland to the UK can be seen as occurring in three distinct waves (Iglicka, 2001). Though some migration occurred prior to the Second World War, it was during and immediately following this era that the UK received its first significant influx of Polish people, many of whom were displaced refugees. The second wave took place during the communist era, which saw a steady trickle of Polish people move to the UK. The flow increased following the collapse of the communist regime, when travel restrictions eased. The most recent wave of migration began on May 1 2004, when Poland, along with seven other central and Eastern European countries, collectively referred to as the 'A 8 ', joined the European Union (EU), initiating a new era of movement of people across Europe. Of those A8 citizens migrating to the UK since 2004 , approximately $66 \%$ have been Polish. It is estimated that the Polish born population of the UK grew from 75,000 in 2003 to 532,000 in 2010 (ONS, 2011).

\section{Review of literature}

Psychological impact of migration

Since the early-twentieth century, researchers have repeatedly found higher rates of psychological disorder in migrant groups (e.g. Bhugra, 2004; Burnett \& Fassil, 2002; Cochrane, 1977; GarzaGuerrero, 1974; Ødegaard, 1932), suggesting that the migration experience is inherently stressful. It is acknowledged that migration is a complex and multi-faceted phenomenon, which includes a range of groups with different histories and reasons for migrating, including voluntary and involuntary migrants. In common with findings from studies of other migrant groups, higher rates of mental illness have been found for Polish migrants (e.g. Cochrane, 1977; Evert, 1996; Malzberg, 1963). How relevant these findings are to post-2004 migrants in the UK is uncertain since the migrants of these earlier studies represent previous waves of Polish migration and arguably endured greater hardships, including war, poverty and permanent separation from families. The most recent migrants, in contrast, have freely moved from Poland without having to overcome many of the obstacles faced by their predecessors.

Furthermore, their profile differs from previous generations, for example they are younger and many more of them are university graduates (Burrell, 2009), which may provide an advantage in the labour market. Indeed, recent evidence shows the number of jobs in the UK requiring a degree is now greater than the number of jobs requiring no qualification (Felstead, Gallie, Green, \& Inanc, 2013).

It is helpful to elaborate on the generational distinction by providing some sociohistorical context. In 1989, democratic rule was re-established in Poland and in 2004 Poland joined the EU. Since this time, through a policy of economic liberalisation, Poland has seen consistent economic growth and increasing privatization, in essence, becoming more and more like its neighbours in Western Europe. It may appear, therefore, that recent Polish migrants are better equipped, both practically and psychologically, to adapt to life in the UK.

Certainly there is evidence of recent Polish migrants successfully integrating into UK society. For example, Burrell (2009) and Eade and Garapich (2009) refer to the development of strong social 
networks and the preponderance of Polish shops, newspapers and websites. Further evidence of their establishment may be seen in an employment rate (for A8 migrants) that, since 2005, has been several percentage points higher than the UK average (Gillingham, 2010).

Other evidence paints a less idyllic picture. For example, a report carried out by the Joseph Rowntree Foundation (Anderson, Ruhs, Rogaly, \& Spencer, 2006) found that although employment rates were high for A8 migrants, work conditions were often arduous and jobs were more likely to be temporary. Pollard, Latorre and Sriskandarajah (2008) also note the incongruence in the tendency for highly qualified recent Eastern European migrants to be employed in low-skilled jobs. Eade and Garapich (2009) report other challenges faced by Polish migrants, including poor housing and a lack of entitlement to welfare benefits.

Evidence also suggests that the pattern of elevated rates of mental health problems found in earlier migrants from Poland is continuing with the current wave. Lakasing and Mirza (2009) refer to reports of exploitation, poverty, loneliness and poor physical health among 'A8 Poles', as some of the factors impairing well-being. Kozlowska, Sallah and Galasiński (2008) collected data from 144 post-accession Polish migrants to the UK using the General Health Questionnaire 28. They found that almost half the group presented with symptoms of psychological distress - approximately double the prevalence rate found in the general population.

The experience of migration is affected by a wide range of contextual factors. While higher rates of mental health problems have been found in migrant groups, there is significant variation in frequency. Evidence regarding the psychological impact of migration for post-2004 Polish migrants is similarly mixed.

Adaptive processes

Factors affecting adaptation to a new culture may include external factors such as social status, poverty, cultural differences, how a person (or group) is received by the resident society, language problems, social support, employment, finance and housing (Berry, 1992; Littlewood \& Lipsedge, 1989). Additionally, internal factors, such as personality and one's ability to adapt, are also relevant (Bhugra, 2004). Berry (1992) conceptualises the adjustment experience as a process of acculturation, during which migrants adopt one of four possible 'strategies': integration, assimilation, separation or marginalisation.

According to Berry, the strategy of integration, that is, engaging with the new culture whilst maintaining the old, is the most adaptive, whereas other strategies are associated with greater frequency of psychological problems.

Theories of identity may provide a useful framework to understand internal processes of adaption. Breakwell's (1986) identity process theory (IPT) holds that an individual's psychological wellbeing is dependent on the maintenance of a coherent sense of self, guided by four principles: self-esteem, self-efficacy, continuity and distinctiveness. When an individual encounters a social context whose structure contrasts with the individual's existing identity, this, Breakwell argues, constitutes a threat to identity, activating a response in the form of a coping strategy to maintain the four guiding principles. 
The compatibility of individual values with the new culture may be of particular relevance in the process of adaptation. Schwartz and Bardi (1997) conducted a crosscultural study, comparing the values of individuals across different Eastern and Western European countries, hypothesising that basic human values were influenced by the political system operating in the individual's society. They found that people living in communist societies were likely to place more importance on values such as conservatism and hierarchy, and were likely to place less significance on values such as personal autonomy and egalitarianism. This may have particular relevance for the participants of this study, whose values and consequent identity structures may diverge from those of their parents due to the different political climates each generation was exposed to.

\section{Methodology}

Interpretative phenomenological analysis

The aim of the research was to explore the experience of migration, acknowledging the significance of social and political context in shaping that experience. Though it can be argued that several qualitative approaches share this aim, in interpretative phenomenological analysis (IPA) socially contextualised experiential understanding is emphasised (Moran, 2000; Smith, 2008), indicating its suitability for this study.

Interpretative phenomenological analysis is focused on understanding and describing lived experience. It attempts to get alongside the participant's subjective world, acknowledging social and political context and emphasising the researcher's role in the interpretative process (Smith, 2007). Small sample sizes are recommended to enable a richer understanding of the material.

\section{Participants}

Eight participants (seven females and one male) volunteered to be interviewed. All had been in the UK since May 2004 for a minimum of 12 months. Table 1 provides basic demographic information for the group.

Table 1. Participant group demographics (pseudonyms are used throughout)

\begin{tabular}{|l|l|l|l|l|l|}
\hline Participant & Age & $\begin{array}{l}\text { Employment } \\
\text { status }\end{array}$ & $\begin{array}{l}\text { Relationship } \\
\text { status }\end{array}$ & $\begin{array}{l}\text { Time in the } \\
\text { UK } \\
\text { (years) }\end{array}$ & $\begin{array}{l}\text { Educational } \\
\text { attainment }\end{array}$ \\
\hline Danuta & 30 & $\begin{array}{l}\text { Accounts } \\
\text { assistant }\end{array}$ & Single & 4 & Graduate \\
\hline Anna & 27 & $\begin{array}{l}\text { University } \\
\text { administrator }\end{array}$ & Single & 3 & Graduate \\
\hline Ewa & 33 & $\begin{array}{l}\text { IT } \\
\text { Professional }\end{array}$ & Single & 3 & Post-graduate \\
\hline Pawel & 27 & $\begin{array}{l}\text { Support } \\
\text { worker }\end{array}$ & Single & 3 & Graduate \\
\hline Magda & 23 & $\begin{array}{l}\text { Volunteer } \\
\text { worker }\end{array}$ & Single & 1 & Graduate \\
\hline Barbara & 31 & $\begin{array}{l}\text { Executive } \\
\text { assistant }\end{array}$ & Single & 4 & Graduate \\
\hline
\end{tabular}




\begin{tabular}{|l|l|l|l|l|l|}
\hline Monika & 29 & $\begin{array}{l}\text { Trainee/ } \\
\text { assistant } \\
\text { psychologist }\end{array}$ & Single & 5 & Post-graduate \\
\hline Kasia & 22 & $\begin{array}{l}\text { Student/ } \\
\text { nanny }\end{array}$ & $\begin{array}{l}\text { In } \\
\text { relationship }\end{array}$ & 3 & Undergraduate \\
\hline
\end{tabular}

Data collection

The research was carried out in accordance with the ethical guidelines of the British Psychological Society (2006) and the University of East London. Data was collected through individual, face-toface, semi-structured interviews (see Appendix 1 for interview schedule), conducted by the first author. Interviews were conducted in English (without an interpreter) and were audio-recorded and transcribed by the first author. Participation required fluency in English.

Steps taken to minimise researcher bias focused on promoting transparency, for example keeping a research diary (see Appendix 2), from pre-data collection to write-up, in order to identify assumptions and reflections provoked throughout the research process and to acknowledge their potential influence on the research. Other steps to minimise bias included having regular consultations with my research supervisor and explicitly encouraging openness at the beginning of interviews.

\section{Analysis}

The analytic process consisted of the following three stages.

\section{Stage 1}

Reading and re-reading each interview transcript, making notes alongside the text, focusing on three different aspects of the material: 'descriptive', 'linguistic' and 'conceptual' (for an example of this process, see Appendix 3 ). As suggested in the literature, applying this approach facilitates a more indepth understanding, moving from surface-level descriptions to interpretative insights (Smith, Flowers, \& Larkin, 2009).

\section{Stage 2}

The next stage involved encapsulating the comments made during the initial phase, identifying the essential meaning of a section of text, whilst referring to its context in the transcript as a whole. As the stage evolved, themes were collapsed, discarded and merged until a sense of coherence was reached, leading to the eventual formulation of a Table of super-ordinate themes and related subthemes.

\section{Stage 3}

In the final stage eight Tables of themes were generated. Identifying connections, patterns, similarities and differences led to grouping, organising and relabeling and, eventually, to the development of a master Table of themes (see Appendix 4). 


\section{Analysis}

Analysis of the eight interview transcripts led to the development of 4 master themes and 11 subordinate themes. The main findings are summarised below, encapsulated under the headings In pursuit of more freedom and Disconnection.

In pursuit of more freedom

A strong sense of Poland being a constraining society that inhibits individual growth was conveyed by this particular group of participants and was referred to as an important motivating factor in their decision to migrate. Magda makes specific reference to a sense of repressive homogeneity, which she links to Poland's communist past:

... because we were under communism for so many years I think like sometimes Polish society is like a grey mass, like everyone is the same, everyone does very similar things, and if you find a job you should do your best to keep this job and not change it because it's not good.

In the following excerpt, Kasia describes her experience of Poland as restrictive and rigid:

... Poland is such a pessimist country [laughs] ... I think there's more opportunity in England, and in Poland I kind of felt like there are certain ways that everyone goes and you have to go that way ... there's not much choice in what you can be, what you can do.

Danuta describes a similar sense of restriction and constraint, linking it with the power of Polish political organisations:

... I start realising that it is hard in Poland, there are still the same people with a social mindset who might, you know, block me because I'm working for the European Institution but someone is telling me, well if you don't join the 'blar' political party then you're not going any further ...

The theme of constraint is also present in a perception of Poland as intolerant of difference and lacking openness. Ewa provides an example of feeling stifled by Poland's homogeneity, something that she feels unable to tolerate for prolonged periods:

I can't be there for too long because the society is so homogenous, you know, it's just one type of people; everyone thinks the same, everyone looks the same, and if you would wear something different ... you wouldn't feel accepted.

Here there is a sense that individual freedom of expression is constrained by cultural norms and expectations. Inherent is a suggestion that to adopt a position outside of societal convention is to risk being ostracised.

A different example of constraint is provided by Barbara, who describes a sense of being constrained in employment opportunities due to gender discrimination:

In Poland it's completely different, it's hierarchy everywhere, women sometimes are discriminated, not everywhere, but the tendency is rather, you know, if you're a woman it's difficult to find a job or more difficult to find a job.

This she contrasts with her experiences in the UK: 
I didn't experience any discrimination of my gender, background, ethnicity, nothing like that, religion, so it was really great experience because I think Poland is very, very intolerant country, so I felt very welcome here when I came and I think this is what helped me to make the decision to stay, definitely, probably the main factor. If I felt discriminated I wouldn't be here, I'd prefer to go to my country but because people are very tolerant, this is what I like, so probably this is what I would miss in Poland.

\section{Disconnection}

Despite participants' appreciation of life in the UK, a sense of disconnection is also evident in their accounts. For example, Monika considers a perceived aloofness of British people:

I think that there is something about different way of maybe socialising. Erm, maybe there's something about English people ... I, I don't really think that, it's like, this is a brilliant country to come here because I don't, like I said, there's not much kind of negative attitudes, but at the same time people aren't that really kind of interested and, it's like indifferent outlook I would use, is the word that comes to my mind.

Magda also refers to this experience:

I miss my friends a lot and I think it's, it's kind of different quality of relationship in Poland and here. I mean here I met plenty, many, many people, but there are only few that I can, you know, talk very openly about things and problems I have er because English people [have] I think this kind of, kind of attitude that they are not very willing to talk about your problems and I'm, I'm, I think I just got used to in Poland, you know, to talk about everything with my very close friends.

Barbara refers to feeling disconnected from her family and her obligations towards them:

I feel that I'm, I think I'm missing on something, erm, my relationship with my parents is very strong, erm, I think they do need me and it's kind of sometimes a sense of guilt that maybe I shouldn't be here, erm, maybe I should be with them, but on the other hand I think it's my life.

Anna captures a sense of tension with regards to her friends and family and her life in the UK:

I'm sort of, you know, I'm torn ... one leg in Poland and one is here.

Summary of findings

For all participants the drive to experience a greater sense of freedom is central in their decision to migrate. Their migration can therefore be regarded as a reaction to inhibitory processes experienced in Poland. These apparent gains from the migration experience are contrasted with feelings of disconnection associated with missing closeness in relationships in the UK.

\section{Discussion}

In pursuit of more freedom

Participants' appreciation of life in the UK centres on freedom, and they appear united by a motivation to feel less restricted in their lives. Their pursuit of freedom may be understood by 
referring to Maslow's (1943) theory of human motivation, which consists of a hierarchy of needs, where basic needs are represented by those that are essential to survival, such as food and shelter. Maslow proposes that that when lower-order needs are met, people look to further enhance their lives and self-esteem, ultimately and ideally leading to what he describes as 'self-actualisation', that is, achieving one's potential. In this context, the participants' motivation to migrate may be understood as a response to an inhibitory external factor that must be overcome if they are to live according to a true sense of self.

It is acknowledged that whilst Maslow's theory of human motivation may be thematically appropriate, its theoretical context may be regarded as problematic due to its ego-centric position and original application to twentieth century North American, middle-class society (e.g. Gambrel \& Cianci, 2003). Given this criticism, a rejection of Maslow's theory may be advised. However, whilst acknowledging the theoretical problems of Maslow's ego-centric, mono-cultural perspective, it is argued that his theory of human motivation is made applicable in the current study as it supports the contention that participants are previously socialised to a Western, post-industrial social context and come with an internalised individualist societal perspective.

With reference to identity process theory (Breakwell, 1986), in the case of the participants it is contended that the threat to identity originates not from the new culture but from the old, as evidenced by participants' accounts of Poland as hindering their self efficacy.

It is argued that participants, as the first post-communist generation, have incorporated individualist values, associated with societal changes taking place in Poland since 1989. These are found to be incompatible with the entrenched, ethno-centric structures of the Polish establishment, causing a threat to identity.

The openness and tolerance that participants perceive in the UK, together with the diversity of London's population, may facilitate acculturation and integration. Phinney, Horenczyk, Liebkind and Vedder (2001) suggest that societies that embrace multiculturalism enable migrants to adapt more successfully. Returning to Maslow, it could be argued that for the participants the UK provides an environment of acceptance, which Maslow (1943) sees as an essential condition required to reach a self-actualised state.

Rather than migration threatening identity, as found by Timotijevic and Breakwell (2000), it is argued that the participants, prior to migrating, are already socialised to a more Western, individualist outlook, which Polish society is perceived to inhibit and which the UK is seen to embrace. Thus, in IPT terms, migration may remove the threat to identity, thus enabling the path towards selfactualisation. Hence, it is the context of their migration in which Maslow's Western construct is made relevant.

\section{Disconnection}

Despite the sense of freedom that participants associate with the UK, six of the group describe missing closeness and refer to experiencing a sense of disconnection regarding relationships with British people, indicating that forming deeper relationships may be problematic. Possibly this difficulty arises due to the socio-cultural differences between Poland and the UK. For example, the differing values attached to the collective and the individual, as described by Hofstede (2001), who 
argues that there exists a greater psychosocial reliance on family and friends in Poland than in the UK. Bhugra (2004) asserts that migrants moving from collectivist to individualist societies may have difficulty settling in to the host culture if their personal outlook is also collectivist.

From the perspective of identity process theory (Breakwell, 1986), participants' difficulty relating to others may be understood as a conflict between pre-existing values and the values of the new culture, leading to identity threat and giving rise to a sense of disconnection. This perspective fits with Berry's (1997) contention that socio-cultural adaptation to the new country may be affected by the extent to which relationship expectations are met.

Length of residence has been identified as a factor affecting socio-cultural adaptation and may therefore be relevant to participants' sense of disconnection. Berry (1997) refers to evidence that over time, through a process of adjustment, migrants eventually settle on the most functional acculturative strategy, indicating that social relationships improve. Ward and Rana-Deuba (1999) similarly argue that socio-cultural difficulties gradually diminish as the length of stay in the host culture increases, providing greater opportunity to form social relationships. This also suggests that the length of time that participants plan to stay in the UK may influence the degree of their investment in host culture relationships, which may determine the level of connectedness that they experience.

\section{Summary and conclusion}

It is argued that the socio-economic landscape of their formative years in Poland has facilitated the participants' adaptation to life in the UK. Whilst the individualistic characteristics of UK society may correspond with their need to develop independently, a consequent cost is the sense of disconnection associated with the discrepancy between social/relational expectations and lived experiences.

For most migrants, migration consists of gains as well as losses (e.g. Berry, 1992; Ward, Bochner, \& Furnham, 2001). For the participants, the perceived gains of migration, that is, greater opportunities for self-actualisation, may offer sufficient defence against the experiences of disconnection, though the potential psychological distress associated with the sense of disconnection remains valid and would be worthy of further exploration.

A study of this size has obvious limitations regarding generalisability. Additionally, the use of English in interviews may have restricted participants' ability to express themselves fully. Further, interviews were conducted by a British citizen and it is acknowledged that this may have influenced participants to portray the UK in a more positive light.

The focus of the study was on those Polish people living in London and it is uncertain how applicable these findings are to the experiences of Polish people living elsewhere in the UK. Recent findings indicate that Polish migrants are now spread throughout England and Wales (e.g. ONS, 2011). Hence, future research focusing on Polish people living outside London, particularly those living in rural communities, may be of particular value. A further caveat concerns the demographic focus of the study. All participants were young university graduates and seven of the eight were female. Obviously, this sample is not representative of the experiences of all Polish migrants, and further 
research focusing on the experiences of those from different age groups and socio-economic backgrounds would be beneficial.

\section{Notes on contributors}

Dr Paul O'Brien is a Health and Care Professions Council registered psychologist working in adult mental health services. He has a strong interest in cross-cultural psychology.

Prof. Rachel Tribe is currently employed in the School of Psychology, University of East London. She has published widely in the areas of culture and mental health and has worked in a range of countries. She is a Chartered Psychologist.

\section{References}

Anderson, B., Ruhs, M., Rogaly, B., \& Spencer, S. (2006). Fair enough? Central and East European migrants in low-wage employment. York: Joseph Rowntree Foundation.

Berry, J. W. (1992). Acculturation and adaptation in a new society. International Migration, 30, 6985. doi:10.1111/j.1468-2435.1992.tb00776.x

Berry, J. W. (1997). Immigration, acculturation and adaptation (Lead article). Applied Psychology: An International Review, 46, 5-34. doi:10.1080/026999497378467

Bhugra, D. (2004). Migration and mental health. Acta Psychiatrica Scandinavica, 109, 243-258. doi:10.1046/j.0001-690X.2003.00246.x

Breakwell, G. M. (1986). Coping with threatened identities. London: Methuen.

British Psychological Society. (2006). Code of ethics and conduct. Leicester: Author.

Burnett, A., \& Fassil, Y. (2002). Meeting the health needs of refugees and asylum seekers in the UK: An information and resource pack for health workers. London: Directorate of Health and Social Care.

Burrell, K. (Ed.). (2009). Polish migration to the UK in the 'new' European union. Surrey: Ashgate.

Cochrane, R. (1977). Mental illness in immigrants to England and Wales. An analysis of mental hospital admissions, 1971. Social Psychiatry, 12, 25-35. doi:10.1007/BF00578979

Eade, J., \& Garapich, M. P. (2009). Settling or surviving in London? The experience of Poles and other A8 migrants in a global city borough. In J. Eade \& Y. Valkanova (Eds.), Accession and migration: Changing policy, society, and culture in an enlarged Europe (pp. 143-166). Surrey: Ashgate.

Evert, H. (1996). Polish community mental health profile: A guide to clinicians and service providers. Melbourne: Victorian Transcultural Psychiatry Unit.

Felstead, A., Gallie, D., Green, F., \& Inanc, H. (2013). Skills at work in Britain: First findings from the skills and employment survey 2012. London: Centre for Learning and Life Chances in Knowledge Economies and Societies, Institute of Education. 
Gambrel, P. A., \& Cianci, R. (2003). Maslow's hierarchy of needs: Does it apply in a collectivist culture. Journal of Applied Management and Entrepreneurship, 8(2), 143-161.

Garza-Guerrero, A. C. (1974). Culture shock: Its mourning and vicissitudes of identity. Journal of the American Psychoanalytic Association, 22, 408-429. doi:10.1177/000306517402200213

Gillingham, E. (2010). Understanding A8 migration to the UK since accession. [pdf]. Office for National Statistics, 1-26. Retrieved from:

http://www.ons.gov.uk/ons/rel/migration1/migrationstatistics-

quarterly-report/november-2010/understanding-a8-migration-to-the-uk-since-accession.pdf

Hofstede, G. (2001). Culture's consequences: Comparing values, behaviors, institutions, and organizations across nations (2nd ed.). London: Sage.

Iglicka, K. (2001). Poland's post-war dynamic of migration. Hampshire: Ashgate.

Kozłowska, O., Sallah, D., \& Galasiński, D. (2008). Migration, stress and mental health: An exploratory study of post-accession Polish immigrants to the United Kingdom. (Unpublished). University of Wolverhampton, Wolverhampton.

Lakasing, E., \& Mirza, Z. A. (2009). The health of Britain's Polish migrants: A suitable case for history taking and examination. British Journal of General Practice, 59(559), 138-139.

doi:10.3399/bjgp09X406992

Littlewood, R., \& Lipsedge, M. (1989). Aliens and Alienists: Ethnic minorities and psychiatry (2nd ed.). London: Routledge.

Malzberg, B. (1963). Mental disease among Polish-born and native whites of Polish-born parentage in New York State, 1949-1951. Mental Hygiene, 47, 421-451.

Maslow, A. H. (1943). A theory of human motivation. Psychological Review, 50, 370-396. doi:10.1037/h0054346

Moran, D. (2000). Introduction to phenomenology. London: Routledge.

$\varnothing$ degaard, $\varnothing$. (1932). Emigration and insanity. Acta Psychiatrica Neurologica Scandinavia Supplement, 4, 1-206.

Office for National Statistics. (2011). Polish people in the UK. Newport: Author.

Phinney, J. S., Horenczyk, G., Liebkind, K., \& Vedder, P. (2001). Ethnic identity, immigration, and wellbeing: An interactional perspective. Journal of Social Issues, 57, 493-510. doi:10.1111/00224537.00225

Pollard, N., Latorre, M., \& Sriskandarajah, D. (2008). Floodgates or turnstiles? post EU enlargement migration to (and from) the UK. London: Institute for Public Policy Research.

Schwartz, S. H., \& Bardi, A. (1997). Influences of adaptation to communist rule on value priorities in Eastern Europe. Political Psychology, 18, 385-410. doi:10.1111/0162-895X.00062 
Smith, J. A. (2007). Hermeneutics, human sciences and health: Linking theory and practice. International Journal of Qualitative Studies on Health and Well-being, 2, 3-11. doi:10.1080/17482620601016120

Smith, J. A. (Ed.). (2008). Qualitative psychology: A practical guide to research methods. London: Sage.

Smith, J. A., Flowers, P., \& Larkin, M. (2009). Interpretative phenomenological analysis: Theory, method and research. London: Sage.

Timotijevic, L., \& Breakwell, G. M. (2000). Migration and threats to identity. Journal of Community and Social Psychology, 10, 355-372. doi:10.1002/1099-1298(200009/10)10:5<355::AIDCASP594>3.0.CO;2-Y

Ward, C., Bochner, S., \& Furnham, A. (2001). The psychology of culture shock. London: Routledge.

Ward, C., \& Rana-Deuba, A. (1999). Acculturation and adaptation revisited. Journal of Cross-Cultural Psychology, 30, 422-442. doi:10.1177/0022022199030004003 


\section{Appendix 1. Interview schedule}

(1) What factors led you to make the decision to migrate?

(2) How much preparation was involved prior to migrating?

(3) Before migrating, what were your expectations?

(4) Is there anything that you found difficult when you first arrived or afterwards?

(5) How did you deal with these difficulties?

(6) How did your expectations compare to your experiences since migrating?

(7) How do you feel you were/are received by the residents in this country?

(8) How do you think you've adapted to life in this country?

(9) What has helped you overcome challenges?

(10) How would you describe your relationship with the country you left?

(11) Has this perception changed during your time here? Do plan to stay in the UK?

(12) Do you think you have gained anything from migrating, on a personal as well as a practical level?

(13) On reflection what would have helped you settle after migrating?

(14) Looking back, is there anything you would have done differently?

(15) What would you advise a Polish person who is thinking of moving to the UK?

(16) Is there anything else related to being a migrant or having migrated that you think is important to talk about? 


\section{Appendix 2. Research diary}

Sample excerpts:

. What are my assumptions of post-2004 Polish people in the UK? I am aware of a stereotypical strong work ethic. I am also conscious of supposing that the majority of recently arrived Poles are employed in mainly manual work and that their main motivation for being in the UK is financial. This understanding has been fuelled by media representations, which, prior to collecting data, has provided me with my main source of knowledge of this group. I am aware of the dangers of holding assumptions and hope that by acknowledging them here I can reduce their unhelpful influence on the research process.

. What is the influence of growing up in a communist country? Is there a greater sense of collectivism and what impact might this have on moving to an individualist society? Will negative aspects of living in the UK emerge, e.g. the experience of materialism and alienation in a consumer society? Friendliness in the UK is initially met with suspicion. This is a likely influence of a culture of mistrust inherent in Polish society. This leads to thoughts about the prevalence of informers and authoritarian policing in communist Poland. The impact of such experiences on the individual may be significant. But, I must be careful not to assume about cultural phenomena and its impact. Possibly my perception is skewed due to growing up in the UK and being socialised by Western values and capitalist democracy.

. Participants talk about the use of technology as a way to keep in touch with family and friends back home. This causes me to think about the impact of phenomena such as the Internet, Skype and budget air travel. Distances between nations appear to have narrowed through technological advances. Does this perhaps make the experience of migration in current times easier? This also causes me to think about the differences between the experiences of recent Polish migrants and the experiences of Poles who migrated in previous waves. Not only technology but also the very ifferent historical context of previous waves.

. The determination expressed by participants to improve their lives and to reach their potential causes me to think of Maslow's theory of self-actualisation. Possibly moving to the UK represents a more fertile environment in which to achieve inner drives. Is living in Poland perceived as restricting opportunity to self-actualise? This would fit with the sense of constraint apparent in many participants' descriptions.

Important to keep in mind that self-actualisation is a Western concept. Self-actualisation may be represented by a more socio-centric position in collectivist societies, however.

. Participants represent the first post-communist generation to migrate from Poland. Possibly some of the tension experienced relates to being caught between two cultures, e.g. desire to pursue individual motivations and obligation to family.

. Might Poles returning to Poland experience acculturation difficulties? 


\section{Appendix 3. Example of early analytic process: excerpt from Ewa}

Descriptive/conceptual and linguistic comments Original transcript - lines 202-220 Emerging themes

Disliking homogeneity of Poland

Preferring diversity of UK

Exclamation (!)

Feels freer in UK

Reflecting on English reserve

$\mathrm{E}$ : I can't be there for too long because the society is so homogenous, you know, it's just one type of people, everyone thinks the same, everyone looks the same, and if you, I don't know, if you, even, if you would wear something different, you'll be like, 'what!', you know, they, you wouldn't feel accepted, you wouldn't feel yeh, so there is...

Poland as stifling in its homogeneity and lack of freedom of expression

Need to feel free and accepted

Empathy with host population

Conscious of self as outsider - enables patience in making friends

Normalising - aids adaptive

Ability

I: So it seems, you feel a bit freer over here then perhaps?

Reluctance to criticise UK?

My influence?

E: Yeh definitely, definitely.

P: Right, erm, so how do you feel you've been er received by, you've already touched on this, but erm, how, how do you feel you've been received by the, the residents of this country or, you know, the natives, if you like.

S: Ok this is erm, I think many people would say, oh English people are reserved and all this, I think it's not true because erm, I think you will feel it in any place where you come to when you're new er, well I feel it, that, you know, everyone else has already have their net of friends and they don't have this need for making new friends, so obviously er, when I'm a new person I have to make most of the effort to sort of, you know, make contacts. Erm so yeh I can understand this and it's nothing er bout English people or any, anyone else really, it's just normal, you know, people who have grown up er here have had their lives here, their own friends and stuff, they know what they're doing in their free time and when you'renew you have to somehow fit into it. 


\section{Appendix 4. Master table of themes (excerpt)}

\begin{tabular}{|c|c|}
\hline \multicolumn{2}{|c|}{ Master table of themes for the group } \\
\hline Master theme 1: Relating to Poland & \\
\hline $\begin{array}{l}\text { Freeing self from perceived constraints of } \\
\text { Poland }\end{array}$ & Page/line \\
\hline \multicolumn{2}{|l|}{ Monika: } \\
\hline $\begin{array}{l}\text { Urge to separate from home. Sense of being tied } \\
\text { to Poland. Find self/develop separate identity }\end{array}$ & $3 / 104-108,10 / 432$ \\
\hline Poland as limiting freedom & $1 / 4-5,3 / 98-100$ \\
\hline Sense of escaping constraints of Poland & 2/91-92, 5/189-191, 6/233-236, 9/370-372 \\
\hline Perceiving Polish culture as rude & 4/139-142, 146-147, 169-171 \\
\hline \multicolumn{2}{|l|}{ Magda: } \\
\hline Poland as homogenous and insular & $1 / 7-18,4 / 181-186,14 / 619-623$ \\
\hline Negative perception of Poland & $3 / 106-108,4 / 181-186$ \\
\hline Inflexibility in Poland & 7/313-319 10/428-437 \\
\hline \multicolumn{2}{|l|}{ Pawel: } \\
\hline Feeling trapped - motivation to migrate & $3 / 92-98$ \\
\hline Rejecting constraints of conservative culture & $10 / 422-430$ \\
\hline $\begin{array}{l}\text { Freedom from constraints of Poland/overcoming } \\
\text { suppression }\end{array}$ & 4/173-179 \\
\hline Polish culture of mistrust & $10 / 428-442$ \\
\hline \multicolumn{2}{|l|}{ Barbara: } \\
\hline $\begin{array}{l}\text { Perceiving Poland as a constraining, inflexible } \\
\text { culture }\end{array}$ & $\begin{array}{l}\text { 5/202-207, 213-219, 8/364-374, 9/405-416, } \\
12 / 512-515\end{array}$ \\
\hline \multicolumn{2}{|l|}{ Ewa: } \\
\hline Perceiving Poland as stiflingly homogenous & $5 / 201-206$ \\
\hline $\begin{array}{l}\text { Perceiving Poland as inhibiting freedom of } \\
\text { expression }\end{array}$ & 5/204-206 \\
\hline \multicolumn{2}{|l|}{ Kasia: } \\
\hline Perceiving Poland as constraining & 1/10-16, 3/98-105, 4/175-184, 5-217-225, \\
\hline
\end{tabular}




\begin{tabular}{|l|l|}
\hline & $6 / 247-251$ \\
\hline $\begin{array}{l}\text { Perception of Poland as stifling independence } \\
\text { and blocking self-actualisation }\end{array}$ & $1 / 10-16,4 / 175-184,6 / 238-251$ \\
\hline $\begin{array}{l}\text { Unwillingness to accept perceived subjugating } \\
\text { conventions of Polish culture }\end{array}$ & $4 / 179-184,6 / 239-251$ \\
\hline $\begin{array}{l}\text { Rejecting Polish conventions/traditional } \\
\text { expectations }\end{array}$ & $4 / 179-184$ \\
\hline Polish culture clashes with personal values & $4 / 175-179,5 / 192-194,198-202$ \\
\hline Motivated to free self from constraints of Poland & $3 / 98-105,4 / 175-184$ \\
\hline Danuta: & $15 / 680-684$ \\
\hline Obstacles/constraints re. living in Poland & $3 / 134$ \\
\hline Poland as lacking opportunities & $2 / 52-55,12 / 523-524$ \\
\hline Urge to be free & $19 / 856-866$ \\
\hline Aspiring to break free from cultural baggage & $1 / 44-45$ \\
\hline Eager to escape Poland & \\
\hline
\end{tabular}

